\section{Weathering the Euro Crisis in the Adhesives Industry}

The German adhesives industry can look back over a successful 2012. The adhesives and chemicals company Bodo Möller Chemie is also on track for success.

A S we have already reported, according to the German Adhesives Association the volume of adhesives and sealants produced in Germany reached a record level of 1.4 million tonnes by the end of 2012. This amounts to 14 times the weight of Europe's entire gold reserves or around 139 Eiffel Towers. The growth in production is expected to continue in 2013.

As Frank Haug, managing director of the Bodo Möller Chemie Group explains: "There are very few industries that do not need adhesives. Many modern manufacturing methods and materials require the use of specialist adhesive systems, including the production of cars, tablet computers and wind turbines. Soldered, bolted and riveted joints are no longer the first choice."

The Bodo Möller Chemie Group is also on track for success. With a comprehensive product portfolio that includes epoxy resin, polyurethane and methyl methacrylate adhesives, together with sealants and additives, the wholesaler

and distributor achieved a global turnover of around EUR 42 million last year. Managing director of Bodo Möller, Frank Haug, explains the company's success in terms of a combination of consultancy and distribution: "The rapid pace of technological developments over recent years has led to constantly changing requirements for adhesive products. With our tailor-made solutions, we are in an ideal position to provide targeted support for our innovation-led customers." The company's growing customer base includes firms from industries such as electronics, aerospace, composites, paper and packaging, together with car, commercial vehicle and transport system manufacturers. At 11 sites worldwide, in locations which include South Africa, France and Scandinavia, the Bodo Möller Chemie Group sells adhesives, composites and additives for plastics and coatings.

For more information, please contact: Bodo Möller Chemie GmbH, www.bm-chemie.de

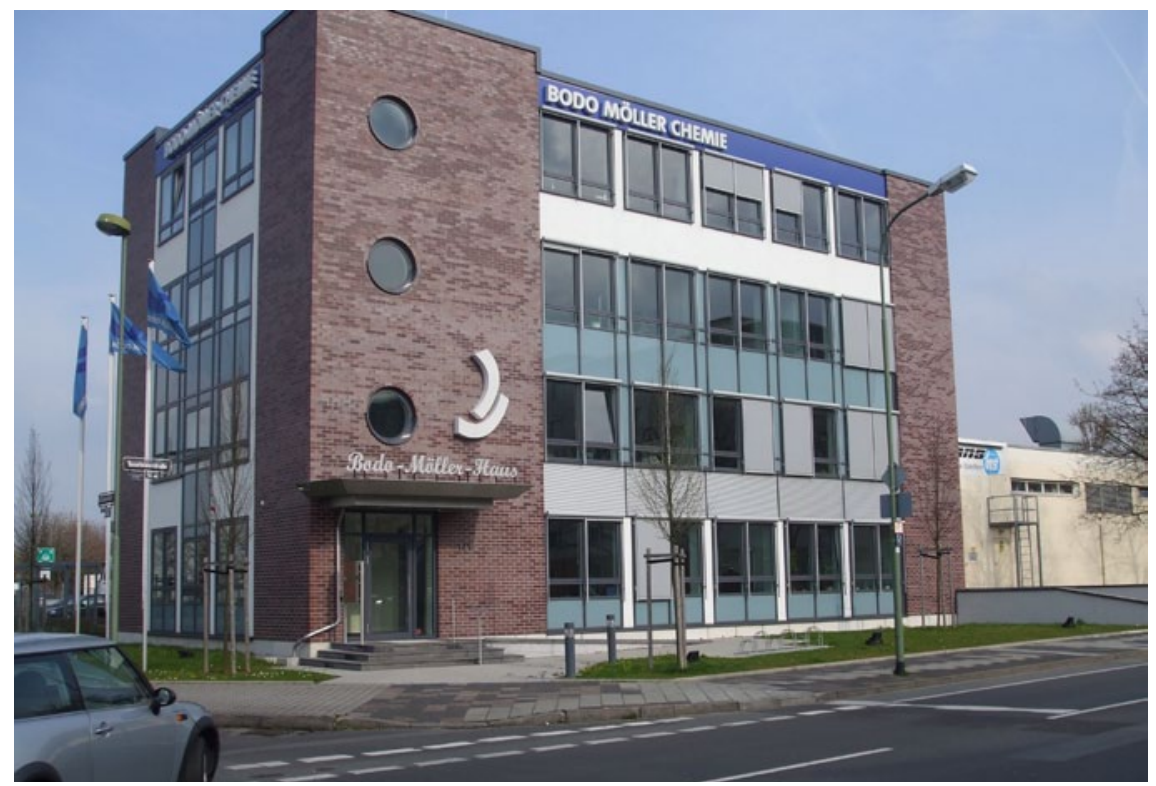

\section{Plastics Processing Fair in Poland}

Erom 7 to 10 May 2013, around 700 ex-

- hibitors from more than 30 countries will be presenting their products at Plastpol, the 17th International Fair for Plastics and Rubber Processing in the Polish city of Kielce. The organisers expect more than 17,000 visitors to attend, who will be coming to find out about the latest developments and trends in the world of plastics.

The focus of this year's event is on the newest methods of processing plastics and rubber and the increasing integration of state-of-the-art IT systems into all areas of plastics processing. This will be the 17th time that the event has been held and it is no longer just the largest international specialist fair for the plastics industry in Poland, but also the leading plastics processing exhibition in Central and Eastern Europe. For more information, please visit: www.targikielce.pl.

\section{Byk Additives \& Instruments Invests in North America}

Work to construct a new 3-storey production building has begun on the newly acquired company grounds of Byk USA in Wallingford, Connecticut, which is scheduled for completion in 2014.

"This investment in Wallingford underlines once again our aspiration to grow on the North American market and to produce as many products as possible locally," said Dr. Roland Peter, President Division Byk Additives \& Instruments. The overall project, which will cost roughly 36 million euros, represents an important milestone in the global corporate strategy of BYK Additives \& Instruments and is also the biggest investment of the Altana Group to date as a whole outside Germany. 